\title{
Mercados Informales y Violencia(s) en Buenos Aires
}

\author{
Informal Market and Violence(s) in Buenos Aires
}

\section{Mercados Informais e Violência(s) em Buenos Aires}

\author{
Mariano Perelman \\ Consejo Nacional de Investigaciones Científicas y Técnicas, Buenos Aires, Argentina
}

\section{RESUMEN}

En este artículo me interesa mostrar las múltiples formas que adquiere(n) la(s) violencia(s) en la constitución de los llamados mercados informales/ ilegales. El artículo recupera el material etnográfico de dos trabajos de campo desarrollados en Buenos Aires. Uno realizado entre 2002 y 2017 con recolectores informales de residuos -conocidos como cartoneros o cirujas - y otro hecho entre 2011 y 2017 con vendedores ambulantes. A partir de indagar en diferentes temporalidades y espacialidades de estas dos actividades quiero mostrar el modo en que la violencia es plural tanto en sus formas como en sus efectos. Me interesa señalar que la violencia es constitutiva de los circuitos de comercio.

Palabras claves: Venta ambulante, Recolección informal de residuos, Violencia física, Violencia moral, Circuitos de comercio.

\section{ABSTRACT}

In this article I am interested in showing the multiple forms that violence takes in the constitution of informal / illegal markets. The article is based on the ethnographic material of two fieldworks carried out in Buenos Aires. One developed between 2002 and 2017 with informal waste pickers - known as cartoneros or cirujas and another fieldwork made between 2011 and 2017 with street vendors. By investigating the different temporalities and spatialities of these two activities, I want to show the way in which violence is plural both in its forms and in its effects. I am interested in pointing out that violence is constitutive of circuits of commerce.

Keywords: Ambulant vending, Informal garbage collection, Physical violence, Moral violence, Circuits of commerce. 


\section{RESUMO}

Neste artigo interessa-me mostrar as múltiplas formas que adquire(m) a(s) violência(s) na constituição dos chamados mercados informais/ ilegais. O artigo recupera o material etnográfico de dois trabalhos de campo desenvolvidos em Buenos Aires. Um realizado entre os anos de 2002 e 2017 com catadores informais de resíduos - conhecidos na Argentina como cartoneros ou cirujas - e outro realizado entre 2011 e 2017 com vendedores ambulantes. A partir de indagações sobre as diferentes temporalidades e espacialidades dessas duas atividades quero mostrar como a violência é plural, tanto nas suas formas quanto nos seus efeitos. Interessa-me assinalar que a violência é constitutiva dos circuitos de comércio.

Palavras-chave: Venda ambulante, Catadores informais de residuos, Violência física, Violência moral, Circuitos de comércio.

\section{INTRODUCCIÓN}

En este artículo me interesa mostrar las múltiples formas que adquiere(n) la(s) violencia(s) en la constitución de los llamados mercados informales/ ilegales. El artículo recupera el material etnográfico de dos trabajos de campo desarrollados en Buenos Aires, Argentina. Uno realizado entre 2002 y 2017 con recolectores informales de residuos-conocidos como cartoneros o cirujas - y otro hecho entre 2011 y 2017 con vendedores ambulantes.

La violencia es una categoría que excede por mucho el mero uso de la fuerza física. Es una relación/ interacción que puede involucrar daños físicos, materiales y morales (CARDOSO DE OLIVEIRA, 2008; MISSE, 2016; PIRES, 2011) y que adquiere diferentes formas desde la violencia física a la moral (PITA, 2019; SEGATO, 2010).

En ambas experiencias de investigación me encontraba con relatos y hechos que podían ser considerados como "violentos": golpes entre recolectores y entre vendedores, conflictos con la policía y con vecinos, insultos, miradas despreciativas. A partir de indagar en diferentes temporalidades y espacialidades de estas dos actividades quiero mostrar el modo en que la violencia es plural tanto en sus formas como en sus efectos.

El texto avanza en mostrar que la relación entre ilegalidad y violencia no es evidente sino más bien una forma de ver y de intervenir sobre el mundo. Me interesa señalar que la violencia es constitutiva de los circuitos de comercio. Según Zelizer (2011) cada circuito económico y de comercio tiene una frontera, un conjunto de lazos interpersonales significativos, 
unas transacciones económicas asociadas y un medio de intercambio. Los circuitos económicos tienen sus particularidades a partir de acuerdos, prácticas, informaciones, obligaciones, derechos, símbolos y medios de intercambio. Entonces, mostraré que la violencia como práctica múltiple es parte de esos lazos y forma parte de las asociaciones transaccionales, así como de los medios de intercambio.

Para ello el texto recorre diferentes tiempos y lugares en los que se desarrollan las actividades: en el caso de los recolectores analizaré dos momentos -el basural hasta 1970- y el trabajo en las calles a partir de 2001. En el caso de la venta ambulante me dedicaré, principalmente, a la venta en trenes haciendo alusión a otros momentos y a otros espacios (como las calles). Mostraré que en algunos momentos algunas prácticas violentas aparecen como normales. No uso aquí normal como en otros estudios sobre la violencia en los que se suele referir a prácticas cada vez más recurrentes, o sea como normalización. Lo normal no implica aquí naturalización (BERMÚDEZ, 2011, 2015; EPELE, 2011). Dice Bermúdez (2015, p. 456) en relación a las muertes de jóvenes que "podríamos señalar también que el ejercicio de imputación de rasgos tales como "normalización" o "rutinización" a ciertos procesos sociales, parecerían conllevar el supuesto de que, al incorporarlos como parte "natural" del acontecer de sus vidas, las personas dejarán de reaccionar frente a determinados acontecimientos como la violencia o la muerte violenta. Es decir que la no participación de familiares o vecinos dentro de organizaciones especializadas o movimientos sociales, sería aparentemente explicada por los efectos de esa normalización, y por tanto, esa "inacción" o "pasividad" termina por allanar el camino a interpretaciones socio-céntricas, clasificando a estas muertes como no lloradas ni sentidas".

Al pensar en normal, me refiero a una relación con las normas. Y las normas son usadas y movilizadas por los actores. Así, no pienso que lo normal sea resignación, inactividad o pasividad. Antes bien, la violencia como norma permite recuperar agencias, usos y disputas.Y también comprender relaciones de poder y procesos de desigualdad.

El texto no tiene pretensiones comparativas. Sin embargo, pensar estos trabajos en paralelo permite iluminar las complejidades y las multiplicidades de formas que adquiere la violencia en una misma, pero también en diferentes actividades. También, permite mostrar el modo en que la multiplicidad de procesos ocurren en "los mercados informales". Si el Estado aparece como regulador que posibilita inscribir ciertas actividades y marcar estos pasos entre lo ilegal y lo legal, también es cierto que son las propias acciones que podríamos considerar no "legales" sino "normales" las que configuran los mercados "informales". El abordaje de los dos casos en diferentes momentos permite mostrar también la pertinencia de pensar la violencia legítima (e ilegítima) como una acción espacializada. Desde esta perspectiva, pensar la violencia en los 
mercados informales permite iluminar entonces, no sólo la normalidad de ciertas prácticas, sino cómo éstas son posibles de ser inscriptas en la gramática de la ilegalidad y de la violencia en términos morales.

Existe un campo de discusión sobre los mercados informales que muestra que las fronteras entre los diferentes universos son una construcción móvil, en las que los límites son porosos (TELLES; HIRATA, 2010) y borrosos. Este campo reconoce que las prácticas no son meramente legales o ilegales, sino que se construyen en un juego de poder (TELLES, 2009). Si bien es posible apreciar en el campo este complejo entramado de "mundos" también es cierto que existen actores que buscan definir e instaurar a las personas y las actividades dentro del marco de lo legal o ilegal. Pensar lo legal- ilegal no refiere sólo al campo de lo jurídico o económico sino también social. Con esto no niego la existencia de los campos formales e informales como productores de sentidos. Como plantean Kessler y Merklen (2013, p. 19) "No se trata, sin embargo, de suponer una "zona gris" donde actores y prácticas definidas como legales se imbrican con otras consideradas ilegales, cada una de las cuales, legales o ilegales, estarían determinadas de una vez y para siempre. Lejos de ello, los límites borrosos entre lo legal y lo ilegal se van redefiniendo en forma casi constante, y esa porosidad de límites es también intrínseca a cada actor y a cada tipo de práctica. Un rasgo de este límite borroso es la existencia de movilidades laterales: un mismo actor, una misma mercancía, en momentos diferentes, por ejemplo, puede pasar de lo legal a lo ilegal para, más tarde, otra vez ser legalizado".

Me interesa pensar entonces aquí casos donde la violencia se dibuja y desdibuja y que va conformando el circuito de comercio mismo. La venta ambulante y el cirujeo se diferencian de otras actividades donde la violencia está socialmente reconocida y cuestionada (FELTRAN, 2019; HIRATA; GRILLO, 2019; HIRATA, 2019). No ocurre así con los cartoneros y los vendedores que pueden movilizar socialmente diferentes sentidos para instaurar su actividad en lo legal y, sino, en lo legítimo. No es mi intención, entonces, indagar aquí sobre las prácticas violentas en los barrios ni en otros posibles entramados violentos que se producen en la vida cotidiana. Me interesa pensar el lugar que la violencia tiene en la articulación de un circuito de comercio. En este sentido, retomo aquí la perspectiva que plantea el carácter social de la economía (MOTTA et al., 2014; NEIBURG 2010; PERELMAN, 2017) que debe tener en cuenta "la relación entre ideas económicas - aquellas producidas por especialistas - e ideas y prácticas ordinarias" (RABOSSI, 2019, p. 718), pero que debe exceder el mundo de "lo económico". La relación violencia- mercados informales ilumina el carácter complejo de las "esferas" que se entrelazan para construir formas de acceder a la vida.

A continuación, abordaré el caso del cartoneo en sus dos momentos para luego desar- 
rollar el circuito de la venta ambulante.

\section{EL CARTONEO}

La recolección para uso o para venta de materiales reutilizables de la basura (conocida como cirujeo, cartoneo, recolección informal) adquirió visibilidad con el crecimiento de personas realizando la actividad en el espacio público hacia fines de la década de 1990. Fue luego de la "crisis de 2001" en Argentina que el cirujeo se transformó en un problema público. El mercado de compra- venta de elementos sacados de la basura, sin embargo, cuenta con una prolongada historia en el que la violencia ha tenido diferentes formas y efectos.

\section{Primer momento: La Quema}

La Quema del Bajo Flores fue en un inmenso basural a cielo abierto que funcionó desde mediados de la década de 1910 hasta 1977, cuando la última dictadura cívico-militar (19761983), a partir de una serie de transformaciones urbanas decidió modificar el sistema de recolección y disposición de residuos ${ }^{1}$ y transformó la zona a partir de la construcción de una serie de parques (COSACOV et al, 2011).

Durante varias décadas el circuito del cirujeo se desarrolló casi íntegramente alrededor de La Quema, al que la basura llegaba desde los distintos barrios porteños para ser volcada. Allí los recolectores esperaban para recuperar materiales que luego serían vendidos a compradores que se acercaban al basural o eran llevados a negocios que se encontraban en las adyacencias del vertedero. Muchos de los recolectores vivían en el basural, otros en las villas miserias aledañas. Una calle dividía La Quema del barrio. Dentro de La Quema, existían ciertas reglas, formas de resolución de conflictos y formas de sociabilidad específicas.

No se podía recolectar en cualquier parte. Los cirujas generaban relaciones personales y formaban bandas en pos de protegerse y dominar el espacio de recolección. Una de las formas sociales legítimas centrales para vivir allí y poder recolectar era la violencia física. Era "mediante la fuerza" que se establecían relaciones, se delimitaban y defendían espacios de recolección. Existían Capangas o Caciques que controlaban esos sitios. Se lograba "con violencia, dando ejemplos de violencia (...) La pelea, una trifulca, te pegaban un tiro, te pegaban un cuchillazo.

1 Sobre la historia del cirujeo ver PAIVA y PERELMAN (2010). 
Y no era sólo él, si vos peleabas, sabías que los otros tenían que apoyar porque estaban todos... había que dar el ejemplo. La fuerza se imponía” según cuenta José, un recolector de La Quema. Otro me explicaba que "había barras que te llevaban de guapo [a la fuerza] si vos eras medio solo, o sea nadie que te respalde, venían dos o tres y te saqueaban la mercadería". Juan, otro recolector, recuerda que "cuando vos juntabas demasiado y estabas solo, ya sabías que te iban a sacar de prepo [a la fuerza]". Para formar parte de las bandas, recuerdan dos viejos amigos de la época, "había que tomar vino" y "arrancar con ellos".

Los estudios que han indagado en el lugar de la violencia como forma de relación social y de estatus han mostrado que la violencia no es un acto irracional. Fonseca (2000) plantea que en Vila do Cachorro Sentado -un barrio de Porto Alegre- es posible encontrar una diferencia entre "ser respetado" (en función de ciertas formas de honor) y hacerse respetar (haciendo uso de la violencia o no rehusando a ella). Una idea similar plantea Garriga Zucal (2012) en Fuerte Apache (Barrio Ejército de Los Andes en el Conurbano Bonaerense) donde la clave para vivir allí era "aplicar mafia". Dice que "El reconocimiento social estaba sustentado en la capacidad para hacerse respetar en términos violentos. Podían "aplicar mafia" aquellos que ante situaciones conflictivas tenían los saberes para defenderse en el lenguaje violento. Este conjunto de saberes que formaban un sistema no solo incluía la posibilidad de enfrentarse a golpes de puño y el uso de armas de fuego, sino también un uso del cuerpo y de las palabras que permitan, en un altercado, demostrar quién es cada uno" (GARRIGA ZUCAL, 2012, p. 5).

Algo similar ocurría en La Quema donde la violencia podía ser implementada como forma de resguardar lo recolectado. En La Quema, la violencia no sólo se ejercía directamente. Gestos, formas de caminar, de acercarse, de aparecer en determinados momentos, de cierta manera, en determinados horarios, eran a veces suficientes. Como plantea Fermín sobre los Capangas "te daban señales de su violencia, te daban señales de que tenías que acatar la orden. No te venían y te pegaban". Al mismo tiempo para ganarse el respeto y poder recolectar, a veces había que responder a las señales.

Como una tarde me comentaba uno de los que había recolectado mucho tiempo en La Quema, vivir allí era "peligroso", había que entender los "códigos" que implicaban "quedarse en el molde", así como también defender a un compañero. A su vez, se ponían en juego construcciones relativas al prestigio y al honor.

La violencia no ha sido la única forma de construcción y mantenimiento de prestigio, pero sí tuvo un lugar central. Allí, la violencia se constituía en una práctica necesaria para poder recolectar. Como me decía uno de los recolectores, refiriéndose a lo que era posible conseguir "El débil quedaba relegado a lo de menos valor" o "tenía que irse porque no se la bancaba". 
Así, la violencia necesaria -en la que se funden el ser respetado y el hacerse respetar- era parte de la recolección misma.

Ser violento, o entender la violencia como relación, es lo que posibilitaba recolectar y sobrevivir. La violencia era constitutiva de este circuito de comercio, tanto como forma para conseguir recursos, cuanto como forma de reconocimiento social. La noción de violencia que aparecía en los relatos de las personas que habían vivido en La Quema, refería explícitamente al uso de la fuerza física que -sin bien cuestionada- estaba legitimada. Y con legitimada refiero a una forma "normal" de relacionarse y de vida.

En este sentido, la violencia "normalizada" aparece como un lenguaje que comunica y organiza, además del circuito, una forma de vida (el cirujeo) en el sentido que le otorga Wittgenstein. Como plantea Das (2016), la naturaleza de la violencia y las formas en que puede ser aceptada como "normal" están de acuerdo con los actores, las prácticas culturales y las legitimidades en contextos y situaciones. $\mathrm{Y}$ esos contextos y situaciones no pueden entenderse sino territorialmente. Tomar como punto de partida la fuerza física no significa dejar de lado las dimensiones estructurales de la violencia (FONSECA, 2000, p. 168). Antes bien, implica mostrar cómo esas dimensiones están normalizadas y son constitutivas de las formas de vida. De esta forma, no es posible entender a la violencia como parte de una cultura popular, de aguante, o marginal. Antes bien, es parte de un entramado de significaciones sociales de un circuito. Esto implica que la violencia puede tener una significación específica dentro y como parte de ese circuito siendo diferente en otros contextos.

Los límites de La Quema marcaban una frontera no sólo física sino también moral en torno al uso (legítimo) de la violencia. Durante el trabajo de campo decenas de veces escuché, tanto a los ex recolectores de La Quema como a los vecinos aledaños, referir a La Quema como un lugar "horrible" que "denigraba al barrio", "peligroso", de "mala vida", de "marginales y delincuentes", que los que allí vivían "era por algo". Pero si bien para los vecinos la quema era una "viviente pesadilla y un doloroso suplicio" como puede leerse en las Nostálgicas vivencias el Barrio de Soldati ${ }^{2}$ para los recolectores la visión era diferente.

El circuito de comercio de la basura no terminaba en La Quema. Desde fines de la década del 1940, se fueron instalando galpones de clasificación, así como personas viviendo en las villas que subsistían de los materiales recuperados (SUÁREZ, 1998). Si bien existió un circuito de relaciones tanto al interior de La Quema como en sus adyacencias, lo cual habilita a pensar

2 Nostálgicas vivencias del Barrio de Soldati. Elaboración colectiva de un grupo de vecinos pioneros del Barrio de Villa Soldati en el marco de las semanas de "Historia Viva" convocadas por la Sec. de Cultura de la M.C.B.A. (9-11). La jornada se llevó adelante entre el 23 y el 31 de octubre de 1987. 
que gran parte de la población aledaña tenía, al menos, algún tipo de vínculo (social y/o económico) con la basura, la violencia como forma central de resolución de conflictos y como forma de comunicación legítima tenía límites en La Quema (COSACOV et al., 2011).

Ello era sólo posible porque la violencia era normal. Se debían comprender los usos legítimos de la violencia tanto para aceptar las jerarquías como para mantener el lugar, ya que parte de los códigos referían a tener que ser violento cuando era necesario. La violencia era una forma legítima de relación para la resolución de conflictos, así como de generación de lazos de amistad y enemistad. Era una de las formas para adquirir mayores materiales para poder sobrevivir, hacerse de un nombre y mantener el honor. La violencia en la configuración de La Quema tenía un carácter económico, pero también social. Los cirujas eran conscientes de que los límites de La Quema eran las fronteras de los códigos y de la construcción de legitimidad. Lo que dentro de ella posibilitaba poder sobrevivir, fuera del predio era visto como una suerte de cultura marginal.

\section{Segundo momento. El cirujeo en las calles}

El cierre de La Quema implicó una readecuación de los comportamientos y de las relaciones para poder sobrevivir. Cuando comencé mi trabajo de campo con los cartoneros en 2002, la actividad venía en un fuerte crecimiento como parte de la crisis socio económica que vivió el país durante el fin del período de la convertibilidad (1991-2001). En ese momento, la actividad de recolección estaba prohibida y ya no se hacía en La Quema sino en las calles. La sangrienta dictadura cívico-militar (1976-1983) había cerrado los basurales y creado el CEAMSE con el fin de pasar a un sistema de relleno sanitario. También, entre varios cambios en el sistema de recolección, una ordenanza de 1977 declaraba que, una vez puestos en las veredas, los residuos eran propiedad de las empresas recolectoras.

Si antes los residuos llegaban a los basurales a donde los cirujas iban (o vivían), el nuevo sistema de recolección hizo que los cartoneros tengan que ir a buscar la basura a las calles. Ahora los recolectores debían recorrer largas distancias para llegar a las zonas céntricas de la ciudad y luego llevar la carga para venderla en un depósito. A diferencia de aquellos límites marcados del basural, el territorio hoy se construye a partir de relaciones sociales que están signadas por otras formas de violencia, tanto físicas como morales. Si en La Quema la violencia era parte de una forma de vida, en las calles la violencia no podía ser una expresión pública ni de prestigio entre los recolectores y los productores de residuos.

Según Cardoso de Oliveira (2008, p. 135),

Sempre que se discute a violência como um problema social tem-se como 
referência a idéia do uso ilegítimo da força, ainda que freqüentemente este aspecto seja tomado como dado, fazendo com que a dimensão moral da violência seja pouco elaborada e mal compreendida, mesmo quando constitui o cerne da agressão do ponto de vista das vítimas.

En la calle la violencia es también constitutiva del circuito, pero ha cambiado tanto en términos físicos como morales. Son tanto formas rutinarias, sutiles y difusas como formas claras y precisas $^{3}$.

El trabajo en las calles implicó la existencia de un nuevo circuito de comercio en el que la violencia tenía otro lugar. Si en el período anterior la recolección de residuos dependía en gran medida de la fuerza física que podía ser aplicada, entablar relaciones de afinidad con vecinos de los barrios donde recolectan se transformó en un componente central de la recolección en la calle.

Las diferentes violencias se expresan y se basan en diferentes argumentos morales. Uno central ha sido la ilegalidad e ilegalización de la tarea primero y de los recolectores después. Hasta 2003 estuvo vigente la ordenanza municipal que prohibía la recolección. Sin embargo, la norma lejos estuvo de ser aplicada hasta que se masificó la recolección informal. Luego de su derogación la ilegalización de la tarea por parte de la policía se basó en figuras de los edictos que ya no estaban vigentes (PERELMAN, 2018).

El crecimiento de la actividad comenzó a modificar las relaciones entre los diferentes actores. Las empresas recolectoras comenzaron a intensificar sus demandas contra los cartoneros. En aquel momento las empresas cobraban según la cantidad de basura recolectada. Los cartoneros, al pasar antes que el camión recolector, quitaban caudal de basura. Pero la prohibición de la recolección no puede reducirse a una trama económica ni (i)legal. El cartoneo se transformó en un problema público y en un conflicto urbano. Los cartoneros eran un problema para la seguridad moral de una ciudad que no toleraba la pobreza expuesta (COSACOV; PERELMAN, 2015).

La designación ilegal o legal de ciertas mercaderías depende de su significado contextual para el orden público y para la reacción moral (MISSE, 2018). Lo mismo ocurre con las per-

\footnotetext{
3 Segato (2010) refiriéndose a la violencia de género dice que "La violencia moral es el más eficiente de los mecanismos de control social y de reproducción de las desigualdades. La coacción de orden psicológico se constituye en el horizonte constante de las escenas cotidianas de sociabilidad y es la principal forma de control y de opresión social en todos los casos de dominación. Por su sutileza, su carácter difuso y su omnipresencia, su eficacia es máxima en el control de las categorías sociales subordinadas" (2010, p. 112). La autora entiende por violencia moral a "todo aquello que envuelve agresión emocional, aunque no sea consiente ni deliberada (...) Es importante enfatizar que este tipo de violencia puede muchas veces ocurrir sin ninguna agresión verbal, manifestándose exclusivamente con gestos, actitudes, miradas" (2010, p. 113).
} 
sonas. La recolección es informal en tanto queda fuera de la regulación estatal y se criminaliza en función de formas de pensar el orden social. Los recolectores tensionan y generan conflictos en torno a ciertos órdenes morales. Pero en esa tensión se generan formas de diferenciación de grupos en los que cabe un abanico amplio de prácticas, que van desde la violencia moral hasta la ilegalidad de policías, en pos de controlar el espacio.

Durante 2002 el trabajo de los cartoneros fue puesto en el centro de la escena tanto por argumentos legales como morales: no era una actividad digna de ser hecha para ganarse la vida (PERELMAN, 2011). Más aún, la persecución no se daba solo por ser cartoneros sino también por ser personas fuera de lugar en la ciudad. Recorrían con sus carros los barrios céntricos. No todos tenían "derecho" a la ciudad; no cualquier tarea podía ser llamada trabajo. Y en la calle, los cartoneros debían soportar miradas inquisidoras, expulsiones y detenciones (COSACOV; PERELMAN, 2015; PERELMAN, 2018).

En su trabajo sobre la violencia institucional Pita (2019, p. 81) marca que la categoría de hostigamiento

refiere a prácticas constitutivas de las relaciones entre efectivos de las fuerzas de seguridad y habitantes de los barrios pobres, en particular jóvenes, que se caracterizan por el maltrato físico y verbal, la humillación, la hostilidad, el amedrentamiento, formas de la violencia física y moral que transitan el amplio arco que va de la discrecionalidad, pasando por la arbitrariedad, hasta la ilegalidad flagrante.

La violencia contra los cartoneros se expresa de múltiples formas. No es ya una relación entre recolectores, sino que se expresa en formas de control del espacio, de estar y de moverse por la ciudad.

"La gente cuando te ve, cruza. Piensa que sos un delincuente, que les vas a robar" me dijo una tarde Javier, luego de que un joven cruzase la calle mientras íbamos caminando por un barrio porteño. "Siento un cuchillo en la espalda todo el día" me dijo otro recolector. Decenas de veces presencié situaciones de violencia moral contra los cartoneros.

Ahora bien, Pita (2019, p. 85) dice que el hostigamiento,

antes que registrar una presunta naturalización de la violencia, cuestión a la que se alude con frecuencia a la hora de hablar de sectores populares, lo que resulta de los modos en los que la mayoría de las personas que conviven y negocian con estas practicas abusivas es una experiencia de la injusticia.

En el caso de los cartoneros durante los primeros años en que la actividad se masificó 
ambas cosas se mezclaban: se expresaba cierta aceptación de las condiciones como una experimentación de la injusticia y de la violencia. En parte ello se debía a que tanto los cartoneros como vecinos y diferentes agentes estatales estaban adecuándose a una nueva situación. Y también porque la condición de crisis generaba campos de posibilidades para que estos procesos acontecieran.

La "ilegalidad" de los cartoneros (y del circuito de comercio) fue construida tanto por la policía como por un importante número de vecinos de los barrios en los que recolectaban. La legislación podía ser usada - o no- para perseguir a los cartoneros. Además, ese proceso de ilegalización y de violencia moral y física se expresó de forma diferente contra los recolectores.

Para los carreros -los que recolectan con un carro tirado a caballo-, por ejemplo, fue un discurso del derecho a los animales y las condiciones de los equinos el que generó formas de intervención. Vecinos, asociaciones protectoras de animales, entes estatales comenzaron a perseguir a los carreros para que les "quiten" los caballos por maltrato animal y por "hacerlos víctimas de actos de crueldad”. Mientras los caballos aparecían como las víctimas, los cartoneros como los explotadores. No es mi intención negar el maltrato hacia los animales, antes bien quiero marcar un doble movimiento: los vecinos humanizaban a los caballos y deshumanizaban a los cartoneros.

Durante el trabajo de campo, presencié decenas de detenciones y quitas de caballos. La violencia contra los animales se transformó en un argumento legítimo en pos de la intervención sobre los carreros. Los carreros, en cambio, estaban preocupados por el estado de los caballos "confiscados". Ello era vivido como una arbitrariedad y como formas violentas de imposición que generaban enfrentamientos con el Gobierno de la Ciudad y con las organizaciones de "protección animal".

Para los cartoneros que recolectaban a pie, en cambio, existían otras construcciones de ilegalidad. Muchas de las detenciones o de labrado de actas y confiscación de lo recolectado se basaban en la aplicación de figuras de los edictos policiales como vagancia o merodeo (que se refieren a la actividad de caminar por las inmediaciones de algún lugar con el supuesto fin de robar algo $)^{4}$, aun cuando los edictos policiales habían sido derogados en 1998. Así, la persecución continuó (y se acentuó) una vez derogada la prohibición de recolección.

Además, los vecinos planteaban que los cartoneros ponían en juego la "seguridad" en un sentido amplio, una seguridad moral: eran muchas veces culpabilizados por robos, por dejar la

4 Los debates en torno al código de convivencia urbano dan cuenta de este accionar policial y de cierto sentido (común) en torno a la construcción y control de las poblaciones "peligrosas” (TISCORNIA, 2008). 
calle sucia, por no respetar las normas tanto legales cómo tácitas del espacio donde circulaban.

La violencia física, pero sobre todo moral - como lo marcan de diferentes formas Segato (2010), Cardoso de Oliveira (2008) o Pita (2019) - se presenta en el campo de formas distintas, a veces de maneras más difusas que otras. Sin embargo, es una violencia cotidiana que tiene fuertes efectos en la producción de grupos sociales. Como he desarrollado en otros trabajos (COSACOV; PERELMAN, 2015; PERELMAN, 2017a), las formas de habitar el espacio -a partir de los procesos de negociación en las interacciones en el espacio público- son formas de construcción de desigualdad social.

De esta forma, si en La Quema podemos pensar a la violencia como parte del circuito de comercio (informal), en las calles la violencia no será una práctica habitual de los recolectores -al menos no en las calles- pero sí parte de ese entramado de producción del cartoneo a partir de la intervención de otros actores como los vecinos y el Estado.

La violencia, sin embargo, también es constitutiva del circuito de comercio en la calle. Esas violencias fueron configurando formas de estar y de relacionarse con los otros actores. Como dije, los cartoneros fueron configurando sus trayectos por la ciudad a partir de la creación de relaciones estables con ciertos vecinos. Ello les posibilitó generar confianza y romper con el estigma del cartonero en tanto persona moral, en tanto actor fuera de lugar. La personalización de la recolección -aun sin que la violencia desaparezca- posibilitó la recolección en espacios que les eran ajenos.

Por otro lado, también como parte del circuito debe entenderse la construcción de la (i)legalidad ya que ha tenido una fuerte impronta en el modo en que los recolectores pueden circular por la ciudad. Si en el período anterior, la violencia aparece como un componente de la forma de vida, en este nuevo período la violencia -no sólo física sino también moral- surge como una negación de una forma de acceder a recursos. Si en el período anterior la violencia es una forma de regulación interna, en este segundo caso es utilizada como forma de construcción de este circuito desde "afuera".

Así la violencia puede pensarse en relación con lo planteado por Cardoso de Oliveira y Cardoso de Oliveira (1996) en torno al "reconocimiento" y a los derechos de ciudadanía. Ellos piensan la relación de "reconocimiento, moral y eticidad" como formas de construcción de legitimidad, del "vivir bien" y del "deber" en el marco de normas compartidas o de una "ética discursiva". En los cartoneros existe una pugna por el reconocimiento de su actividad en tanto trabajo (con fuertes implicancias por la histórica ligación entre ciudadanía y trabajo) (PERELMAN, 2011). Los cartoneros buscan legitimidad a partir de conceptualizar a la actividad como un trabajo digno en el marco de normas y expectativas socialmente compartidas. 
Las formas de ocupación del uso del espacio público por parte de los cartoneros de una forma desigual y las posibles utilizaciones de la violencia "legítima" por parte del Estado, entonces, contribuyen a la producción de formas de ganarse la vida desiguales. Boltanski (2016) plantea que el límite entre lo legal y lo ilegal suele también volver sobre la frontera del Estado. Esas fronteras remiten a formas sociales de pensar el orden y la normalidad que exceden las prácticas estatales. En el caso de los cartoneros en las calles es justamente una violencia por intentar regular esa actividad. Posible gracias a la pugna por insertar la práctica cartonera como ilegal y -cuando no- como ilegítima. En este sentido, a diferencia de otros trabajos en torno a la relación entre violencia e ilegalidad, es posible pensar la violencia como constructora de un límite del orden social y no como una forma legítima de regulación del mercado informal. Es, entonces, parte del circuito.

\section{La venta ambulante}

Antes que de la crisis de 2001 como el caso de la recolección, el circuito de venta ambulante actual es en gran parte producto del crecimiento económico del período posconvertibilidad durante los gobiernos kirchneristas (2003-2015) en los que el consumo popular creció notablemente (GAGO, 2014; KESSLER, 2013, 2014; WILKIS, 2013).

Desde hace tiempo ya algunos grupos han instalado la cuestión de la venta callejera como un problema público ligado a la "ilegalidad" (BELCIC, [2020]; FERNÁNDEZ ALVAREZ et al., 2019; PERELMAN, 2018; PITA, 2012; PITA; PACECCA, 2017). Con la asunción de Mauricio Macri como presidente de la Nación (diciembre de 2015- diciembre 2019), la persecución de los vendedores creció notablemente. Así, durante el 2016 y en los primeros días del 2017, la Ciudad de Buenos Aires fue objeto de desalojos masivos de personas dedicadas a la venta callejera en la ciudad. Las políticas del gobierno nacional de Macri han generado nuevas incertidumbres en el trabajo callejero (BELCIC, [2020]; CANELO, 2019; PITA y PACECCA, 2017).

Por el circuito de venta ambulante circulan una serie de productos que permiten instalarlo como parte de un mercado ilegal: indumentaria y productos de electrónica "truchos", cds y DVDs piratas, entre otras cosas. También otros productos que son cuestionados o sospechados como alimentos en "supuesto" mal estado o prontos a vencer. Sin embargo, como dije, no son sólo las "características" en sí las que instalan un tema como legal o ilegal, sino las relaciones sociales y la capacidad de poder que tienen los diferentes actores por instalar un tema.

También la actividad es fácilmente instalable en el ámbito de lo “informal”. Los productos que se venden quedan por fuera del control impositivo del Estado y usan el espacio público 
"sin permiso". Existen disputas sobre las cosas que circulan -así como sobre el uso del espacio público (FERNÁNDEZ ÁLVAREZ, 2018) - ya que tienen un valor reconocido socialmente. Ello ha generado tensiones y negociaciones con comerciantes y policías (BELCIC, [2020]; PIRES, 2020; PITA; PACECCA, 2017).

En la venta ambulante los pasos por las fronteras porosas y la transitividad de personas entre lo legal e ilegal (KESSLER, 2012; TELLES, 2009; TELLES; HIRATA, 2010) son constantes. Y si bien las personas no suelen tener problemas en hacerlo, tienen efectos cotidianos en el modo en que se producen las interacciones y se constituyen sentidos que luego son re-apropiados en la interacción. Las diferentes formas de venta implican distintos tipos de arreglos con la policía, relaciones con otros vendedores, con los comerciantes o con los compradores. También los juegos de poder aquí son centrales como lo documentan Pires $(2010 ; 2017)$ y Pita (2012a; 2012b) en torno a la venta callejera.

Así como en el caso de la recolección informal, los productos pasan por diferentes manos y "estatus". Algunos salen de grandes fábricas del mercado formal, van a comercios mayoristas donde los vendedores compran para luego vender "informalmente". Otros son productos piratas y pasan por diferentes fases de "ilegalidad": desde su producción a su distribución. Visto en conjunto, la venta ambulante no ha tenido el mismo nivel de persecución.

En el caso de los que ofrecen productos en la vía pública, si bien existen negociaciones entre comerciantes de locales y vendedores, públicamente los primeros se quejan de "competencia desleal". Cuestionan el uso del espacio público para la venta de productos. Argumentan que la calle es "privatizada" por los vendedores. Así, los comerciantes se quejan por el uso ilegal del espacio y por la ilegalidad de las formas de la venta (como el no pago de impuestos o la venta de "cosas truchas"), aun cuando la mayor parte de los comerciantes suelen evadir impuestos o tener empleados "en negro". Sin embargo, mientras una práctica (la de los vendedores) es vista como ilegal, la otra (la propia de los comerciantes) no.

A diferencia de la calle, los que se dedican a ofrecer productos en el transporte público no son vistos como competidores con otros vendedores "formales". Mi trabajo de campo estuvo centrado con este grupo. En especial, con los buscas. Busca proviene de buscavidas. Muchos de estos vendedores comienzan todos los días sólo con el dinero necesario para comprar mercadería para la venta. Los vendedores reivindican la falta de ataduras y la libertad de la tarea, el no “arreglar" con la policía (PIRES, 2010; 2020). Los buscas se configuran en oposición a otros actores que se dedican a la misma actividad (PERELMAN, 2013b; PIRES, 2010). Ser busca es una forma de vida y no sólo una forma de obtener dinero. Es una forma de sociabilidad, de gastar el dinero, de entender el trabajo. 
La venta ambulante en trenes tiene una configuración diferente a la de la venta en la calle. Se constituye en otro circuito en el que la violencia tiene varios usos y significaciones. Mientras la venta en las calles es configurada como ilegal (por lo que se la persigue), la que se realiza en trenes es tenida como informal. Atender a los juegos de poder (TELLES, 2009) permite apreciar los usos diferenciales de la legalidad, la ilegalidad y la legitimidad e ilegitimidad de las prácticas ${ }^{5}$. Procesos que están constantemente en negociación y tensión, pero también producen formas de relación y creación del lazo social asimétrico que produce desigualdad social. El modo en que se puede estar en el espacio público da cuenta de la aceptación o no de las formas de vida digna de los grupos sociales. Más aún el uso del espacio público en tanto productor de renta ha sido objeto de demanda por parte de grupos de vendedores (FERNÁNDEZ ÁLVAREZ, 2018).

Además, existe por parte de los medios de comunicación y otros actores un intento de construcción de la actividad de venta como "mafia" Con ello hacen alusión a una gran organización ilegal piramidal para la venta de productos en los transportes en la que los trabajadores serían explotados por alguien que les da mercadería para vender a cambio de una pequeña remuneración (FERNÁNDEZ ÁLVAREZ, 2019).

Esta visión se ve reforzada desde la mirada externa que ve en el uso de la violencia -legítima desde los vendedores- como ilegal y parte de una cultura marginal por fuera de la regulación estatal.

No es del todo importante si las relaciones son legales o ilegales en sí mismas, sino el ámbito discursivo donde se inscriben en tanto problema público. Como es sabido las palabras tienen fuerza, el decir algo tiene una capacidad performativa que lo inscribe en una arena específica de discusión: hablar de mafias inscribe las prácticas organizativas en el ámbito de lo ilícito y en relación con una práctica violenta.

Como marca Misse,

lo que distinguiría a un mercado formal de un mercado informal sería, en suma, su mayor o menor participación en un conjunto de regulaciones estatales. Sin embargo, la lógica económica del mercado produce relaciones complejas (y muchas veces contradictorias) con esas regulaciones legales. Entre ellas

\footnotetext{
5 El trabajo de María Pita sobre los vendedores ambulantes senegaleses en Buenos Aires es iluminador en ese sentido. En ese caso, la nacionalidad de los vendedores es central en la construcción de territorios sociales y morales de control policial que "falam de uma distribuição desigual da legalidade e dos direitos" (PITA, 2012b, p. 132).

6 Ver por ejemplo https:/www.lanacion.com.ar/opinion/el-combate-de-la-venta-ambulante-ilegal-nid1974719. Accedido el: 20 abr. 2019. https://redcame.org.ar/contenidos/circular/Mapa-de-la-Argentina-Ilegal_hay-662-saladitas-y-86_728-vendedores-informales.8505.html. Accedido el: 20 abr. 2019.
} 
está la de las mercancías cuya oferta (y, en algunos casos, su consumo) es criminalizada [...] El mercado criminalizado es, así, doblemente informal: es necesariamente un mercado informal de trabajo, por la criminalización de las mercaderías que produce, vende o alivia de posibilidad de cualquier regulación formal de las relaciones de trabajo y de las obligaciones tributarias, además de ser un mercado de circulación de mercancías ilícitas, cuya actividad es, en sí misma, criminalizada [...] Ese debilitamiento moral de la designación criminal de una mercancía, la misma dimensión que justificaría, en última instancia, su criminalización, abre innumerables espacios sociales de maniobras más o menos legales o simplemente ilegales (pero moralmente toleradas) para su comercialización (MISSE, 2018, p.190).

Una fría y soleada tarde de julio de 2013 por la tarde iba junto a un vendedor en el tren y bajamos en la estación que suele ser punto de encuentro de un grupo de vendedores. Apenas pisamos el andén notamos que algo pasaba. Tres hombres jóvenes parecían discutir con otro. Desde lejos se veían los movimientos bruscos de sus cuerpos. Pocos segundos después comenzaron los golpes de puños y las patadas. Fueron pocos minutos, ya que el joven al que los otros pegaban salió corriendo y se perdió por los pastizales que rodeaban la estación. El vendedor me miró como enfatizando algo que yo ya sabía y que había varias veces visto: aquello era una forma de resolver conflictos, de delimitar quién podría vender o no.

El lugar de la violencia como forma de obtener un espacio en los trenes ha sido un mecanismo importante durante años (PERELMAN, 2013c). He presenciado decenas de peleas y he escuchado múltiples relatos sobre el lugar de la violencia física para el mantenimiento de los espacios de trabajo. Como dije, esto que forma parte de las relaciones sociales que construyen el mercado de la venta en el transporte público (PERELMAN, 2013b; 2017b) es leído desde el lente de la sospecha (FERNÁNDEZ ALVAREZ, et al., 2019) como una práctica mafiosa.

Si la violencia es una forma de regulación privada, la violencia física y moral contra los vendedores es pública. Si la violencia física debe ser utilizada para poder mantener el espacio, no forma parte de las conductas legítimas a la hora de vender. Aun cuando durante varios años los vendedores de los trenes raramente han estado expuestos a la persecución ${ }^{7}$, la venta como una forma de ilegalismo contribuye a una suerte de derecho precario ${ }^{8}$ que depende de las relaciones de afinidad entre los actores y del contexto político en el que la legislación pueda o no ser usada.

7 Me refiero especialmente a mis primeros años de trabajo de campo entre 2011 y 2015.

8 Retomo aquí la noción de Pires (2017) para el caso brasileño. A diferencia del Brasil donde la figura es parte del "derecho" en este caso lo pienso más como una forma de derecho a la ciudad en el sentido que le da Lefebvre (1968). 
Existe una memoria y una experiencia construida -al igual que en el caso de los cartoneros- a partir de una violencia física y moral contra los vendedores. Al igual que en el caso del cirujeo, los vendedores saben de las posibles persecuciones y que la capacidad de estar en el espacio público depende de las negociaciones. Generar relaciones es una manera de lograr cierta estabilidad.

Los efectos de la violencia son parte del circuito. Ellos son constitutivas de las relaciones y de las obligaciones morales que se entablan. Por ejemplo, como desarrollé en otro lugar (PERELMAN, 2013a, p. 43), la memoria de la violencia y la posibilidad de ser detenidos o de que la mercadería sea confiscada ha generado formas de afinidad entre vendedores y proveedores. Varios vendedores recuerdan, por ejemplo, el momento de la privatización (en la década de 1990) y la persecución policial sobre ellos. En esos tiempos, dice Cacho que "venía la policía. Entonces te levantaban todo, te llevaban a la comisaría, acá en la estación y te hacían limpiar algo. Una vez, nos hicieron bajar unas baldosas de este tamaño [hace un gesto abriendo ambas manos] desde el primer piso. Estuvimos toda la tarde haciendo eso, después nos largaron. Nos confiscaron toda la mercadería (...) No tenía qué vender. Y se compra con lo que se vende. Así que como no había vendido nada no tenía un mango para comprar mercadería. Pero le pedía al Tano y me fiaba [esto es, les dan una cosa y esperan el pago posteriormente], una caja de gaseosas, sabia que después, cuando vendía se la pagaba". Ello ha generado deudas morales que han mantenido relaciones durante años.

No sólo los proveedores son parte de la cadena de predictibilidad ${ }^{9}$. También lo son los otros vendedores, los comerciantes de las estaciones, el personal de control de los trenes y los pasajeros. A partir de relaciones de afinidad es que se configura una red que posibilita la venta. Por ejemplo, muchos vendedores dejan la mercadería en los comercios para no tener que cargarla todo el tiempo. También respetan los códigos de los comerciantes en cuanto a lo que se vende y cuándo se vende. Las relaciones de amistad con el personal de seguridad le garantizan la entrada y la circulación. Con los pasajeros muchos generan una relación personal -incluso vendiendo fiado. Hacerse conocido es una forma de poder trabajar en un contexto de (posible) incertidumbre.

Las formas de estabilización y de relaciones también pueden quebrarse por los insultos morales (PIRES, 2011; 2020) como forma de violencia. Una tarde, un vendedor me contó que había decidido cambiar de proveedor. El proveedor le había recriminado el cambio apelando a una deuda moral: lo había ayudado en momentos en que no tenía dinero para pagarle. El vende-

9 No es sólo la violencia la que construye estas relaciones. Ver Perelman (2013b; 2017b). 
dor también esgrimía razones morales para romper la relación "si, pero ahora no me respetas" fue su respuesta. El vendedor me dijo también que a los puesteros les fiaba la "carga completa" mientras que a él sólo le adelantaba una pequeña parte de lo que iba a ofrecer. Para Cacho, éste era un acto que hablaba de cierta falta de confianza y un des-respeto a alguien que siempre ha tenido códigos.

A la vez, estando en una actividad que es permitida, aunque la legalidad suele disputarse (lo que implica formas cotidianas de violencia moral), los vendedores se construyen públicamente como parte del control del espacio ("mantener la línea limpia", o sea que no haya violencia) y además plantean que están brindado un servicio (venta de productos). La legitimidad que esgrimen los vendedores remite a una forma de control y de seguridad sobre el espacio. Y aquí plantean que, para ello, a veces tienen que usar la violencia física. Es para los vendedores una violencia antes que legítima, moralmente justificada en pos del bien común.

Esto genera, sin embargo, un efecto contradictorio. Para los vendedores es una forma de reivindicar su lugar en la línea a partir de la construcción de una superioridad moral con relación a otros vendedores. Son los que controlan que no haya robos, que los productos que se vendan sean de cierto estatus, etc. Hacia adentro del colectivo de vendedores, estas relaciones personales son necesarias para la fijación de precios, diferenciar horarios y zonas de venta, dividir productos a vender, etc. Se produce así el circuito de comercio. Lo cierto es que la violencia es una forma de mantener el espacio y no dejar entrar a otros vendedores. Para mantener el circuito, los vendedores se reparten los productos que pueden vender, así como buscan ponerse de acuerdo en el precio. Ello no ocurre siempre de manera cordial. Como una tarde me dijo Quique que "si [otro de los buscas] quiere vender a otro precio, lo bajo del tren". Quique logró su espacio en el tren a fuerza de la violencia física. Él es hoy un referente de un importante grupo de vendedores. Muchos acuden a él cuando tienen algún problema, y el recuerdo de su violencia le otorga la capacidad para poder decidir el precio al que ofrecerá su producto.

La forma en que la violencia opera para obtener y mantener el espacio fue recurrente en mi trabajo de campo. Sacar a golpes a otros posibles vendedores ha sido una práctica recurrente y por ello muchas personas piensan en la actividad como violenta y marginal. Ello tiene efectos en la noción misma de legitimidad hacia fuera que es transformada discursivamente en ilegalidad (como mafias). La violencia, así, tiene un lugar múltiple en el circuito de comercio.

Nuevamente se ponen en juego imaginarios en torno a la ilegalidad/marginalidad/ peligrosidad. Los arreglos y las formas de vender están marcadas por las propias formas de ganarse la vida de las personas. La distinción entre un busca y otros vendedores se produce a partir de una serie de prácticas y valores morales que hacen de la venta ambulante un modo de vida. 
Una calurosa tarde de enero de 2012, salíamos al hall central de una de las terminales de tren más grande de Buenos Aires. Ramiro llevaba consigo el bolso en el que guarda las medias que compra en una fábrica cerca de su casa. De repente su mirada se posa por unos largos segundos en dos policías que están parados a unos 5 metros charlando en un puesto de diarios. Me mira y con la cabeza me hace un gesto para que vayamos hacia el otro lado. Ya, a unos metros de distancia, me dice "lo que pasa es que no los conozco y no sé qué pueden hacer o pedirme".

Este tipo de hechos da cuenta, como plantea Pita (2019, p. 90), que "estas fronteras no sólo son porosas, sino que ellas mismas son efecto, en parte, tanto de las normas y facultades y sus características, como de la propia naturaleza de la tarea policial que habilita el pasaje, a veces imperceptible, entre discrecionalidad y arbitrariedad".

La capacidad de negociación, de aceptar, contestar la violencia forma parte de las prácticas cotidianas de los vendedores y tienen efectos en las formas de vender y de moverse. Es por ello que no pueden pensarse sino como parte del circuito. Tanto la violencia física como moral son parte constitutiva del circuito de comercio de la venta ambulante. Circuito con fronteras porosas entre legal- ilegal, entre lo formal e informal. Es un circuito donde diferentes formas de violencia conviven con efectos, formas, modos, legitimidades diferentes. Estas violencias están incrustadas (parafraseando la noción de (POLANYI 2012) sobre el lugar de la economía en los procesos sociales) en el circuito. Y, así, es indisociable de éste.

\section{A MODO DE CIERRE. CIRCUITOS DE COMERCIO, VIOLENCIAS Y DESIGUALDAD}

En este texto busqué reflexionar sobre el lugar de la(s) violencia(s) como partes constitutivas de los mercados de venta ambulante y recolección informal. Intenté iluminar las múltiples formas en que la violencia se manifiesta.

Si los estudios sociales de la economía han mostrado que "la economía" como esfera está signada por los procesos sociales (NEIBURG, 2010), la violencia rara vez es pensada como parte de esta co-constitución. Mi posición ha sido tomar a la violencia (tanto física como moral) como constitutiva de los circuitos económicos y de comercio. Esto es, antes que pensarla como un acto irracional, hacerlo como parte de los procesos económicos. Y es en esta línea que mi texto busca contribuir. 
La violencia, no podemos perder de vista, es una relación de poder y es por ello que parece adquirir cierta "particularidad" en los mercados informales, ya que existen formas legitimadas de intervenir sobre él. Por ello, si bien los límites son porosos, los efectos y la capacidad de ejercer violencia por parte de grupos sobre los "informales" o sobre los que son construidos como "ilegales" es distinta. Atender a la construcción social de estas diferencias es central para entender la producción de las desigualdades sociales. También me parece importante no sólo remarcar que la violencia se ejerce sobre personas y por personas, sino que se hace en un territorio determinado.

La violencia configura modos de relacionarse, de generar asociaciones y formas de estar en el territorio. En este marco es que es posible comprender qué formas de violencias pueden ser toleradas o no, son legítimas o no. Una mirada de las violencias como parte del circuito de comercio permite comprender su carácter múltiple y el lugar que tiene en el mantenimiento del orden. Así, la normalidad de la violencia varía según la configuración.

La legitimidad de las prácticas violentas está territorializada y encuentra sentidos diferentes según el lugar donde se ejerza. La violencia es múltiple en sus ejercicios y en sus efectos. Indagar en los dos casos me permitió mostrar estas complejidades y colocar el acento en el lugar central y múltiple que tiene la violencia en la construcción de circuitos de comercio. O sea, no es posible partir de que la violencia tiene apenas un uso y un efecto. Indagar etnográficamente las interacciones, las prácticas, los discursos permite preguntarse por la violencia antes que darla como una realidad. La normalidad de la(s) -o de diferentes tipos de- violencia(s), entonces, debe entenderse en cada configuración. Así, lo normal puede estar naturalizado o no.

Por último, quiero volver a destacar que, en ambos casos, la violencia es a veces ejercida dentro de los vendedores y entre los cartoneros, y a veces aplicada contra ellos. Que sea parte de un circuito de comercio no implica que no existan formas de dominación, de desigualdad. Aún cuando la violencia es parte del circuito, los efectos que ella tiene producen formas de desigualdad en diferentes dimensiones. Si bien en ambos casos el lugar de la violencia como forma de imposición es innegable, la violencia ejercida sobre ellos es un componente central de la negación de las formas de vida, de las formas de dominación actual y de ejercicio de la violencia institucional. 


\section{REFERENCIAS}

1. BELCIC, Sofía. Control estatal de vendedores callejeros en Río de Janeiro y en la Ciudad de Buenos Aires: una aproximación comparativa a la relación entre vendedores y agentes de control. Antropolítica: Revista Contemporânea de Antropologia, Niterói, n. 50, [2020]. No prelo.

2. BERMÚDEZ, Natalia. Y los muertos no mueren... Una etnografía sobre clasificaciones, valores morales y prácticas en torno a muertes violentas (Córdoba- Argentina). Berlim: Editorial Académica Española, 2011.

3. BERMÚDEZ, Natalia. Etnografía de una muerte no denunciada: Justicias y valores locales en una villa de la ciudad de Córdoba, Argentina. Dilemas - Revista de Estudos de Conflito e Controle Social, v. 8, n 3, p. 455-72, 2015. Disponível em: https://revistas. ufrj.br/index.php/dilemas/article/view/7301. Acesso em: 02 fev. 2020.

4. BOLTANSKI, Luc. Enigmas y complots. Una investigación sobre las investigaciones. Buenos Aires: FCE, 2016.

5. CANELO, Brenda. Modalidades de control de la venta callejera y criminalización de inmigrantes en Buenos Aires. In. MANSILLA, M. J. A.; BOY, M.; ARICÓ, G. Aricó (Ed.) La ciudad mercancía: turistificación, renovación urbana y políticas de control del espacio público. Buenos Aires: Teseo press, 2019, p. 129-48.

6. CARDOSO DE OLIVEIRA, Luís Roberto. Existe violência sem agressão moral? Revista Brasileira de Ciências Sociais, v. 23, n 67, p.135-46, 2008. Disponível em: https://www.scielo.br/scielo.php?script=sci_arttext\&pid=S0102-69092008000200010. Acesso em: 02 fev. 2020.

7. CARDOSO DE OLIVEIRA, Roberto, CARDOSO DE OLIVEIRA, Luís Roberto Ensaios antropológicos sobre moral e ética. Rio de Janeiro: Tempo Brasileiro, 1996.

8. COSACOV, Natalia et. al. De 'la Quema' al parque: Notas sobre las políticas urbanas en la dictadura y la producción de pequeños consensos cotidianos en la Ciudad de Buenos Aires (1976-1983). Sociohistórica/ Cuadernos del CISH, v. 29/30, P. 71-85, 2011. Disponível em: http://www.memoria.fahce.unlp.edu.ar/art_revistas/pr.5626/pr.5626. pdf. Acesso em: 03 mar. 2020.

9. COSACOV, Natalia; PERELMAN, Mariano. Struggles over the Use of Public Space: Exploring Moralities and Narratives of Inequality. Cartoneros and Vecinos in Buenos Aires. Journal of Latin American Studies, v. 47, n 3, p. 521-542, 2015. Disponível em: https://www.cambridge.org/core/journals/journal-of-latin-american-studies/article/ abs/struggles-over-the-use-of-public-space-exploring-moralities-and-narrativesof-inequality-cartoneros-and-vecinos-in-buenos-aires/8812642619A1EBA2C783A5D7571D0DF9. Acesso em: 03 mar. 2020. 
10. DAS, Veena. The Boundaries of the "We:" Cruelty, Responsibility and Forms of Life. Critical Horizons, v. 17, n. 2, p. 168-85, 2016. Disponível em: https://www.tandfonline. com/doi/abs/10.1080/14409917.2016.1153888. Acesso em: 02 fev. 2020.

11. EPELE, María. Morir en los márgenes: políticas de facticidad y muerte- joven en poblaciones vulnerables del Gran Buenos Aires. In: VISACOYSKY, S (Ed.) Estados críticos: la experiencia social de la calamidad. La Plata: Ediciones Al Margen, 2011, p. 176-200.

12. FELTRAN, Gabriel. (Il)licit Economies in Brazil: An Ethnographic Perspective. Journal of Illicit Economies and Development, v. 1, n. 2, p. 145-154, 2019. Disponível em: https://jied.lse.ac.uk/articles/10.31389/jied.28/. Acesso em: 02 fev. 2020.

13. FERNÁNDEZ ÁlVAREZ, María Inés. Nunca mafia. Experiencias de vida y formas de organización de vendedores ambulantes en espacios públicos. In: 13.

FERNÁNDEZ ÁLVAREZ, María Inés et al. Bajo Sospecha. Debates urgentes sobre las clases trabajadoras en la Argentina. Buenos Aires: Callao Cooperativa cultural, 2019, p. 21-41.

14. FERNÁNDEZ ALVAREZ, María Inés. Más allá de la precariedad: prácticas colectivas y subjetividades políticas desde la economía popular argentina. Íconos - Revista de Ciencias Sociales v. 62, p. 21-38, 2018. Disponível em: https://revistas.flacsoandes.edu. ec/iconos/article/view/3243. Acesso em: 15 fev. 2020.

15. FERNÁNDEZ ALVAREZ, María Inés et. al. Bajo Sospecha. Debates urgentes sobre las clases trabajadoras en la Argentina. Buenos Aires: Callao Cooperativa cultural, 2019.

16. FONSECA, Claudia. Família, fofoca e honra. Etnografia das relações de gênero e violência em grupos populares. Porto Alegre: UFRGS editora, 2010.

17. GAGO, Verónica. La razón neoliberal: economías barrocas y pragmática popular. Buenos Aires: Tinta Limón Ediciones, 2014.

18. GARRIGA ZUCAL, José. “Aplicar Mafia”. La violencia como dimensión de un estilo popular. AVATARES de la comunicación y la cultura,n. 3, p. 1-16, 2012. https://1library. co/document/y43xv55z-aplicar-mafia-violencia-dimension-estilo-popular.html. Acesso em: 03 dez. 2019.

19. HIRATA, Daniel Veloso; GRILLO, Carolina. Movement and Death: Illicit Drug Markets in the Cities of São Paulo and Rio De Janeiro. Journal of Illicit Economies and Development, v. 1; n 2, p. 1-14, 2019. Disponível em: https://jied.lse.ac.uk/ articles/10.31389/jied.26/. Acesso em: 02 mar. 2020.

20. HIRATA, Daniel Veloso. Letalidade e ilegalismos de negócios em uma tríplice fronteira sul-americana: Primeira aproximação. Dilemas - Revista de Estudos de Conflito e Controle Social Edição Especial n. 3, p. 173-197, 2019. Disponível em: https://revistas. ufrj.br/index.php/dilemas/article/view/23487. Acesso em: 02 mar. 2020. 
21. KESSLER, Gabriel. Controversias sobre la desigualdad. Argentina, 2003-2013. Buenos Aires: FCE, 2014.

22. KESSLER, Gabriel. Ilegalismos en tres tiempos. In: CASTEL, Robert et al. Individuación, precariedad, inseguridad ¿Desinstitucionalización del presente? Buenos Aires; Barcelona; México: Paidós, 2013, p. 109-166.

23. KESSLER, Gabriel. Movilidades laterales, delito, cuestión social y experiencia urbana en las perisferias de Buenos Aires. Revista de Ciencias Sociales, V. 25, n 31, p.12042, 2012. Disponível em: http://www.memoria.fahce.unlp.edu.ar/art_revistas/pr.10653/ pr.10653.pdf. Acesso em: 15 dez. 2019.

24. KESSLER, G.; MERKLEN, D. Una introducción cruzando el Atlántico. In: CASTEL, Robert et al. Individuación, precariedad, inseguridad ¿Desinstitucionalización del presente ? Buenos Aires; Barcelona; México: Paidós, 2013, p. 9-43.

25. LEFEBVRE, Henri. Le droit à la ville. Paris: Anthropos, 1968.

26. MISSE, Michel. Crimen y violencia en el Brasil contemporáneo: estudios de sociología del crimen y de la violencia urbana. México: CIESAS, 2018.

27. MISSE, Michel. Violência e teoria social. Dilemas - Revista de Estudos de Conflito e Controle Social, v. 9, n. 1, p.45-63, 2016. Disponível em: https://revistas.ufrj.br/index. php/dilemas/article/view/7672. Acesso em: 15 dez. 2019.

28. MOTTA, Eugênia; NEIBURG, Federico; RABOSSI, Fernando, MÜLLER, Lúcia. Foreword: Ethnographies of Economy/ics: Making and Reading. Vibrant - Virtual Brazilian Anthropology, v. 11, n. 1, p. 50-55, 2014. Disponível em: https://www.scielo. br/scielo.php?script=sci_arttext\&pid=S1809-43412014000100002. Acesso em: 03 mar. 2019.

29. NEIBURG, Federico. Os Sentidos Sociais da Economia. In: DUARTE, L. F. D. (Ed.) Horizontes das Ciências Sociais no Brasil. Sao Paulo: ANPOCS; Barcarolla; Discurso Editorial, 2010, p. 225-258.

30. PAIVA, Verónica; PERELMAN Mariano D. Aproximación histórica a la recolección formal e informal en la ciudad de Buenos Aires: la "quema" de Parque Patricios (18601917) y la del Bajo Flores (1920-1977). Theomai, v. 21, p. 134-149, 2010. Disponível em:https://www.researchgate.net/publication/49598399_Aproximacion_historica_a_ la_recoleccion_formal_e_informal_en_la_ciudad_de_Buenos_Aires_la_quema_de_ Parque_Patricios_1860-1917_y_la_del_Bajo_Flores_1920-1977. Acesso: 03 mar. 2020.

31. PERELMAN, Mariano D. Disputas en torno al uso del espacio público en Buenos Aires. Caderno CRH, v. 31, n. 82, p. 87-98 2018. Disponível em: https://www.scielo.br/scielo. php?pid=S0103-49792018000100087\&script=sci_abstract\&tlng=es. Acesso em: 10 dez. 2019. 
32. PERELMAN, Mariano D. Pensando la desigualdad urbana desde el trabajo callejero. In: BOY, M.; PERELMAN, M. (Eds.) Fronteras en la ciudad: (Re)producción de desigualdades y conflictos. [S.1.] Teseo, 2017a, p. 19-44.

33. PERELMAN, Mariano D. Vender nos ônibus. Os Buscas na cidade de Buenos Aires, Argentina. Tempo Social, v. 29, n. 1, p. 69- 87, 2017b. Disponível em: https://www. scielo.br/scielo.php?pid=S0103-20702017000100069\&script=sci_abstract\&tlng=pt. Acesso em: 02 fev. 2020.

34. PERELMAN, Mariano D. Formas sociales de estabilización en actividades informales. Cirujas y vendedores ambulantes en la ciudad de Buenos Aires. Lavboratorio, v. 25, p. 37-55, 2013a. Disponível em: https://ri.conicet.gov.ar/handle/11336/27224. Acesso em: 02 fev. 2020.

35. PERELMAN, Mariano D. Trabajar en los trenes. La venta ambulante en la ciudad de Buenos Aires. Horizontes Antropológicos, v. 19, n. 39, p. 179-204, 2013b. Disponível em: https://www.scielo.br/scielo.php?script=sci_abstract\&pid=S0104$71832013000100008 \& \operatorname{lng}=$ pt\&nrm=iso\&tlng=es. Acesso em: 03 mar. 2020.

36. PERELMAN, Mariano D. Trabajar, Pedir, Vender. El Caso de los vendedores ambulantes en trenes de la Ciudad de Buenos Aires, Argentina. The Journal of Latin American and Caribbean Anthropology, v.18, n. 2, p. 231-250, 2013c. Disponível em: https:// ri.conicet.gov.ar/handle/11336/27463. Acesso em: 15 fev. 2020.

37. PERELMAN, Mariano D. La construcción de la idea de trabajo digno en los cirujas de la ciudad de Buenos Aires. Intersecciones en antropología, v. 12, n. 1, p. 69-81, 2011. Disponível em: https://www.redalyc.org/pdf/1795/179522601006.pdf. Acesso em: 15 fev. 2020.

38. PIRES, Lenin. Mercados informales y la circulación de la tolerancia: mercancías políticas y relaciones entre sociedad y Estado. Cuadernos de Antropología Social, v. 51, 2020. Disponível em: http://revistascientificas.filo.uba.ar/index.php/CAS/article/view/7673/7 187. Acesso em: 15 fev. 2020.

39. PIRES, Lenin. Precários e perigosos: possíveis relações entre formalidade e informalidade em processos de administração de conflitos no Rio de Janeiro. In: GLEDHILL, J.; HITA, M. G.; PERELMAN, M. D. (Eds.) Disputas em Torno do Espaço Urbano: Processos de Produção /Construção e Apropriação da Cidade. Salvador: Editora UFBA, 2017, p. 335-352.

40. PIRES, Lenin. Esculhamba, mas não esculacha! uma etnografia dos usos urbanos dos trens da central do Brasil. Niterói: EdUFF, 2011.

41. PIRES, Lenin. Arreglar não é pedir arrego. Uma etnografia de processo de administração institucional de conflitos no âmbito da venda ambulante em Buenos Aires e Rio de Janeiro. 2010. Tese (Doutorado em Antropologia) - Programa de Pós-Graduação em Antropologia, Universidade Federal Fluminense, Niterói. 
42. PITA, María Victoria. Hostigamiento policial o de las formas de la violencia en barrios populares de la Ciudad de Buenos Aires. Relato de una investigación. Desacatos. Revista de Ciencias Sociales, v. 60, p. 78-93, 2019. Disponível em: https://desacatos. ciesas.edu.mx/index.php/Desacatos/article/view/2091. Acesso em: 10 fev. 2020.

43. PITA, María Victoria. Mitologías porteñas en torno al poder policial. Policía, contravenciones y gestión de ilegalismos en la Ciudad de Buenos Aires. La Biblioteca, v. 12, p.182-209, 2012a.

44. PITA, María Victoria. Poder de polícia e administração de grupos sociais: o caso dos vendedores ambulantes senegaleses na Cidade Autônoma de Buenos Aires. In: TELLES, V. S.; AZAÏS, C.; KESSLER, G. (Eds.) Ilegalismos, cidade e política. Belo Horizonte: Fino Traco, 2012b, p. 109-40.

45. PITA, María Victoria; PACECCA, María Inés. (Eds). Territorios de control policial: gestión de ilegalismos en la Ciudad de Buenos Aires. Buenos Aires: Editorial de la Facultad de Filosofía y Letras Universidad de Buenos Aires, 2017.

46. POLANYI, Karl. La gran transformacion: los orígenes políticos y económicos de nuestro tiempo. México: Fondo de Cultura Económica, 2012.

47. RABOSSI, Fernando. Los caminos de la informalidad. Sociologia \& Antropologia, v. 9, n. 3, p.797-818, 2019. Disponível em: https://www.scielo.br/pdf/sant/v9n3/22383875-sant-09-03-0797.pdf. Acesso em: 03 mar. 2020.

48. SEGATO, Rita Laura. Las estructuras elementales de la violencia: ensayos sobre género entre la antropología, el psicoanálisis y los derechos humanos. Buenos Aires: Prometeo Libros, 2010.

49. SUÁREZ, Francisco. "Que las recojan y arrojen fuera de la Ciudad”, Historia de la gestión de los residuos sólidos (las basuras) en Buenos Aires, Documento de trabajo $\mathrm{n}^{\mathrm{o}}$ 8. Los polvorines, Universidad Nacional de General Sarmiento, 1998.

50. TELLES, Vera da Silva; HIRATA, Daniel Veloso. Ilegalismos e jogos de poder em São Paulo. Tempo Social, v. 22, n. 2, p. 39-59, 2010. Disponível em: https://www.scielo.br/ $\mathrm{pdf} / \mathrm{ts} / \mathrm{v} 22 \mathrm{n} 2 / \mathrm{v} 22 \mathrm{n} 2 \mathrm{a} 03$. Acesso em: 15 mar. 2020.

51. TELLES, Vera da Silva. Nas dobras do legal e do ilegal: Ilegalismos e jogos de poder nas tramas da cidade. Dilemas - Revista de Estudos de Conflito e Controle Social, v. 2, n. 5-6, p. 97-126, 2009. Disponível em: https://revistas.ufrj.br/index.php/dilemas/ article/view/7192. Acesso em: 15 mar. 2020.

52. TISCORNIA, Sofía. Activismo de los derechos humanos y burocracias estatales. El caso Walter Bulacio. Buenos Aires: Editores del Puerto y CELS, 2008.

53. WILKIS, Ariel. Las sospechas del dinero. Moral y economía en la vida popular. Buenos Aires: Paidós, 2013. 
54.ZELIZER, Viviana. Economic Lives: How Culture Shapes the Economy. Princeton: Princeton University Press, 2011.

\section{Mariano Perelman}

Doutor em Antropologia pela Universidad de Buenos Aires, Pesquisador do Consejo Nacional de Investigaciones Científicas y Técnicas. ID ORCID: https://orcid.org/0000-0002-4914-3198. E-mail: mdperelman@gmail.com. 